OPEN ACCESS

Edited by: Janarthanan Jayawickramarajah, Tulane University, United States

Reviewed by:

Apurba Lal Koner,

Indian Institute of Science Education and Research, Bhopal, India

Bang-Jing Li,

Chengdu Institute of Biology,

(CAS), China

*Correspondence:

Reji Varghese

reji@iisertvm.ac.in

Specialty section:

This article was submitted to

Supramolecular Chemistry,

a section of the journal

Frontiers in Chemistry

Received: 25 October 2019 Accepted: 06 January 2020 Published: 28 January 2020

Citation:

Atchimnaidu S, Thelu HVP, Perumal D,

Harikrishnan KS and Varghese $R$ (2020) Efficient Capturing of Polycyclic Aromatic Micropollutants From Water

Using Physically Crosslinked DNA

Nanoparticles. Front. Chem. 8:2.

doi: 10.3389/fchem.2020.00002

\section{Efficient Capturing of Polycyclic Aromatic Micropollutants From Water Using Physically Crosslinked DNA Nanoparticles}

\author{
Siriki Atchimnaidu, Hari Veera Prasad Thelu, Devanathan Perumal, Kaloor S. Harikrishnan \\ and Reji Varghese* \\ School of Chemistry, Indian Institute of Science Education and Research (IISER) Thiruvananthapuram, Thiruvananthapuram, \\ India
}

Design and synthesis of physically (non-covalently) cross-linked nanoparticles through host-guest interaction between $\beta-C D$ and adamantane is reported. Specific molecular recognition between $\beta-C D$ functionalized branched DNA nanostructures (host) and a star-shaped adamantyl-terminated 8-arm poly(ethylene glycol) polymer (guest) is explored for the design of the nanoparticles. The most remarkable structural features of DNA nanoparticles include their excellent biocompatibility and the possibility of various non-covalent interactions with both hydrophobic and hydrophilic organic molecules. Potential of DNA nanoparticles for the rapid and efficient capture of various micropollutants typically present in water including carcinogens (hydrophobic micropollutants), organic dyes (hydrophilic), and pharmaceutical molecules (hydrophilic) is also demonstrated. The capture of micropollutants by DNA nanoparticles is attributed to the various non-covalent interactions between DNA nanoparticles and the micropollutants. Our results clearly suggest that DNA based nanomaterials would be an ideal candidate for the capturing and removal of both hydrophilic and hydrophobic micropollutants typically present in water.

Keywords: DNA nanostructures, self-assembly, micropollutants, water purification, host-guest interactions

\section{INTRODUCTION}

One of the major threats to human health is the occurrence of organic micropollutants such as pesticides, polycyclic aromatic hydrocarbons (carcinogens), pharmaceuticals etc. in drinking water, and hence their detection, capture, and removal from drinking water is extremely vital (Schwarzenbach et al., 2006). Micropollutants typically present in drinking water include both hydrophobic and hydrophilic organic molecules. Activated charcoal was traditionally used as sorbent for the capture and removal of micropollutants from drinking water (Órfão et al., 2006). Though activated charcoal is efficient and successful in removing hydrophobic micropollutants, they often fail in capturing the hydrophilic micropollutants. Nanomaterials offer an alternative and convenient substrate for the capture and removal of micropollutants from water. For example, carbon-based nanostructures such as multi-walled carbon nanotubes (Kuo, 2009), graphene (Xu et al., 2012), and graphene oxide (Gao et al., 2012) were proven to be remarkable adsorbents for organic micropollutants. In the case of carbonaceous nanomaterials, since the adsorption is 
mainly achieved through the $\pi-\pi$ stacking interactions, they were shown to be very efficient for the capturing of polycyclic aromatic hydrocarbons. However, carbonaceous nanomaterials were found not to be a superior adsorbent for hydrophilic micropollutants. Similarly, metal nanoparticles were also found to be promising substrate for the removal of micropollutant from water (Wang et al., 2018). However, the toxicity associated with the metal nanoparticle is a concern. Very recently, supramolecular approaches were also reported for the capture of micropollutants. For example, hydrophobic cavity of $\beta$ cyclodextrin $(\beta-C D)$ was explored for the rapid capturing of different organic micropollutants using a porous $\beta$-cyclodextrinbased polymer (Alsbaiee et al., 2016). In another report, chargetransfer interaction was used for the capturing of polycyclic aromatic hydrocarbons using a semi-rigid cationic cyclophane as the host (Barnes et al., 2012). Even though there are few elegant strategies are reported in the literature, there is always a growing demand for the design of new nanomaterials for the capturing of organic micropollutants that exhibit (i) excellent biocompatibility, (ii) efficient capturing (interaction) toward both hydrophobic and hydrophilic micropollutants, and (iii) non-toxicity.

The unique structural characteristics of DNA such as nanoscale dimensions, predictable secondary structure, ease of synthesis and molecular recognition-directed self-assembly have fascinated scientists to use DNA as a molecular building block for the construction of DNA nanostructures (Seeman, 1982, 2010; Gothelf and LaBean, 2005; Aldaye et al., 2008; Pinheiro et al., 2011; Tørring et al., 2011). Recent years have seen the emergence of extremely complex one-dimensional (1D), 2D, and $3 \mathrm{D}$ nanostructures made of DNA, which have found potential applications in various fields ranging from material science to medicine (Walsh et al., 2011; Jiang et al., 2012; Modi et al., 2013) to nanotechnology (Seeman, 2003; Feldkamp and Niemeyer, 2006; Song et al., 2013; Jones et al., 2015). More interestingly, DNA is known to have efficient non-covalent (physical) interactions with both hydrophilic and hydrophobic organic molecules through various non-covalent interactions such as hydrogen bonding, $\pi-\pi$ stacking, electrostatic interactions etc. (Hannah and Armitage, 2004). Hydrophobic molecules prefers to bind to DNA through intercalation within the nucleobases through hydrophobic interactions. Whereas hydrophilic cationic molecules binds to the phosphate backbone of DNA through electrostatic interaction. The remarkable structural features of DNA including the excellent biocompatibility, efficient non-covalent interactions with hydrophobic and hydrophilic molecules and non-toxicity indisputably suggest that DNA based nanomaterials would be a promising candidate for the capture of organic micropollutants from water. Among the various classes of nanomaterials, nanogels, particularly physically cross-linked, are unique owing to their nanosize, porosity, and high guest encapsulation ability (Yu et al., 2006). Moreover, physically

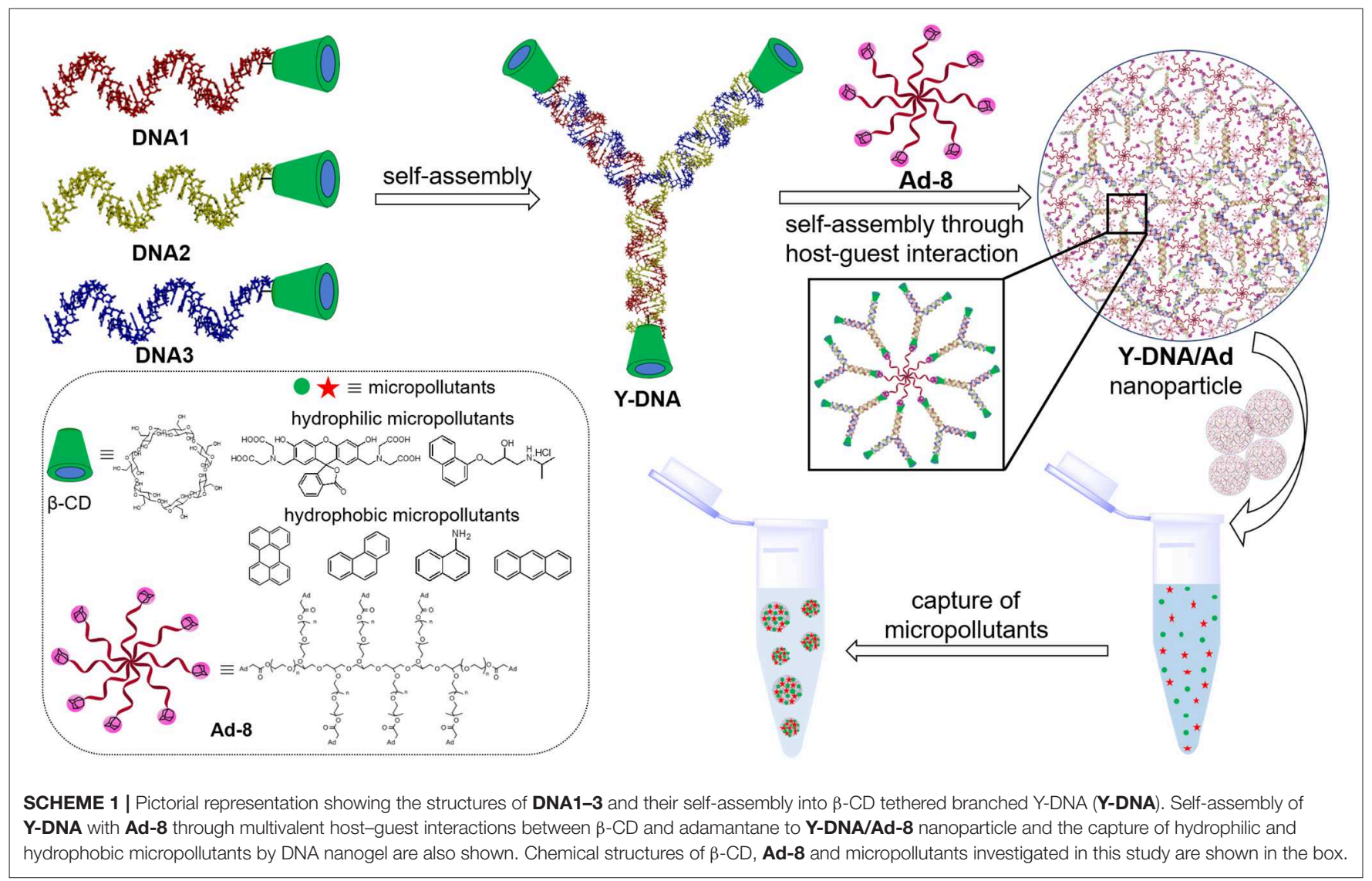


cross-linked nanogels are far superior over the chemically crosslinked counterparts because of their ease of synthesis, reversible and stimuli responsive nature (Mishra et al., 2018). Hence physically cross-linked DNA-based nanogel would be the most ideal candidate for the capture of organic micropollutants from water. Though chemically cross-linked DNA hydrogels have successfully explored for the removal of organic micropollutants from water, there is no report on the use of physically cross-linked DNA nanogels for the capture of micropollutants from water.

Supramolecular interactions have been extensively explored for the design of various soft nanomaterials with remarkable optical and electronic properties (Rest et al., 2014; Taniguchi et al., 2016; Mishra et al., 2018; Zhou et al., 2018). Very recently, we have explored the molecular recognition between $\beta$-CD and adamantane for the design of DNA-based physically crosslinked nanogel (Thelu et al., 2018). We have demonstrated the synthesis of DNA-based nanogel with controllable size using the multivalent host-guest interaction between $\beta$-CD functionalized branched DNA nanostructures as the host and a star-shaped

TABLE 1 | Sequences of DNA1-3.

\begin{tabular}{ll}
\hline DNA & Sequence $\left(5^{\prime} \rightarrow 3^{\prime}\right)$ \\
\hline DNA1 & $\beta$-CD-TTGGATCCGCATGACATTCGCCGTAAGA \\
DNA2 & $\beta$-CD-TCTTACGGCGAATGACCGAATCAGCCTA \\
DNA3 & $\beta$-CD-TAGGCTGATTCGGTTCATGCGGATCCAA
\end{tabular}

adamantyl-terminated 8-arm poly(ethylene glycol) polymer as the guest. The potential of the nanogel as a nanocarrier for targeted drug delivery was also demonstrated. Herein, we report the potential of DNA-based nanogel for the capture of organic micropollutants, both hydrophobic and hydrophilic, from water (Scheme 1). The design of nanogel was already reported by us, and the same strategy was followed for the synthesis of DNA nanogel. This was achieved by self-assembly between multivalent host-guest interaction between $\beta$-CD functionalized branched DNA nanostructures as the host and a star-shaped adamantylterminated 8-arm poly(ethylene glycol) (PEG) polymer as the guest. The size of the nanogel could be controlled by appropriate modulation of the concentration of the guest and host. The potential of the nanogel to capture a series of hydrophobic molecules and hydrophilic molecules are demonstrated. The capture of the molecules into the DNA nanogel network is due to the non-covalent interactions of the micropollutants with the backbone and bases of DNA. Our results clearly show that the DNA based nanogels are promising nanomaterials for the capture of micropollutants.

\section{RESULTS AND DISCUSSIONS}

The synthesis of the 8-arm star PEG polymer, Ad-8 (guest molecule) was achieved by following our previously reported procedure (Thelu et al., 2018). The $\beta$-CD-tethered oligonucleotides (DNA1-3) are complementary to each to form $\beta$-CD-tethered Y-shaped DNA (Y-DNA) and the sequences
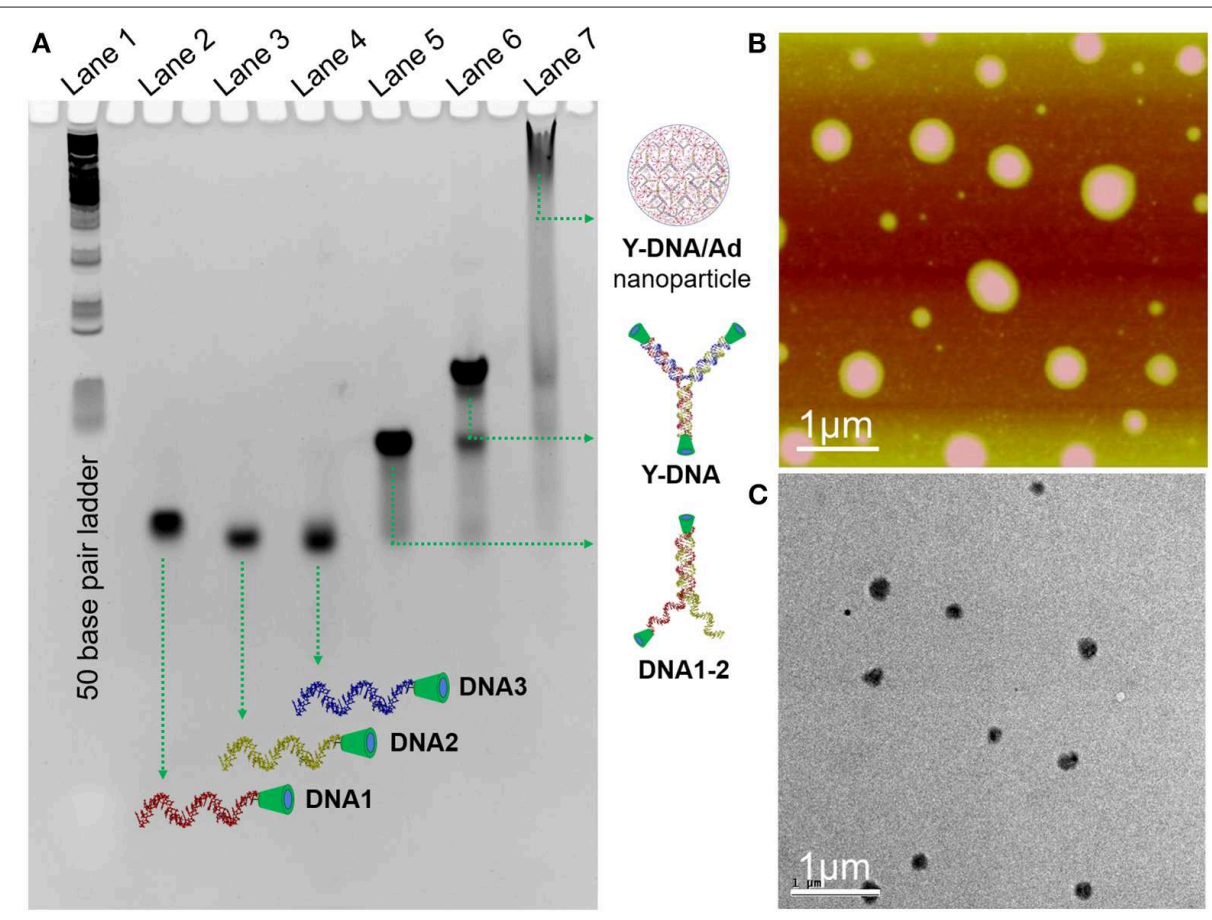

FIGURE 1 | (A) Native PAGE (14\%) analysis of the self-assembly of Y-DNA/Ad-8. L1 for 50 base pair ladder, L2-L4 for DNA1-3, respectively, L5 for the assembly of DNA1 and DNA2, L6 for the assembly of DNA1, DNA2 and DNA3, L7 for the assembly of Y-DNA and Ad-8. (B) Tapping-mode AFM height and (C) TEM images of Y-DNA/Ad-8 nanoparticles, respectively. 
of the DNAs are provided in Table 1. The self-assembly of the oligonucleotides was initially studied using native polyacrylamide gel electrophoresis (PAGE) analyses (Figure 1 and Figure S1). The self-assembly of the $\beta$-CD-tethered Y-shaped DNA (host) was achieved by the self-assembly of equimolar quantities of DNA1-3 in PBS buffer containing $\mathrm{NaCl}(100 \mathrm{mM})$ by annealing from $90^{\circ} \mathrm{C}$ to room temperature following a reported procedure (Um et al., 2006). Native PAGE analyses clearly show that the sequential addition of complementary DNAs leads to the formation of host $\beta$-CD-tethered Y-shaped DNA (Y-DNA) as it is evident from the reduced electrophoretic mobility of the resultant DNA nanostructure compared with the corresponding individual complementary DNA strands. Further reduction in the electrophoretic mobility was observed with the addition of Ad-8 to Y-DNA, which clearly reveals that the self-assembly between Ad-8 and Y-DNA through host-guest interaction between $\beta-C D$ and adamantane resulted in the formation of nanoaggregates for Ad-8/Y-DNA supramolecular complex. Dynamic light scattering (DLS) analyses of Ad-8/YDNA show the formation of aggregated species in solution with diameter in the range of $140-290 \mathrm{~nm}$. Zeta potential $(\zeta)$ measurement reveals a value of $-16.6 \mathrm{mV}$, which suggest the formation of aggregated species decorated with negatively charged DNA. Better insights into the morphology of the aggregates were provided by atomic force microscopy (AFM) and transmission electron microscopy (TEM) analyses. Atomic force microscopic height image of Y-DNA/Ad-8 shows the formation of spherical nanoparticle with diameters in the range of $150-300 \mathrm{~nm}$. The section analyses of the nanoparticle reveal that the average height of the nanoparticle is $\sim 18 \mathrm{~nm}$, which is significantly lower than the corresponding average diameter of the nanoparticles. This indicates significant flattening of the nanoparticles occurs on the mica surface due to their soft nature, which is in accordance with similar soft nanoparticles. In accordance with AFM observations, TEM analyses also show the formation of nanoparticles with diameters in the range of $\sim 250 \mathrm{~nm}$. Microscopic analyses are in good agreement with the DLS data. Microscopic, DLS and PAGE data collectively confirm that hierarchical assembly of Y-DNA and Ad-8 through multivalent host-guest interaction between $\beta$-CD and adamantane leads to the formation of Y-DNA/Ad-8 nanoparticles in water (nanogel).

The most striking features of the nanoparticles include: (i) excellent biocompatibility, (ii) non-toxicity, (iii) hydrophobic pockets, and (iv) anionic DNA backbone, which are ideal for their application as an adsorbent for the capturing of hydrophobic and hydrophilic molecules dissolved in water. This motivated us to explore the potential of the DNA nanoparticles for the capturing of micropollutants typically present in water. We have taken few representative examples for hydrophilic and hydrophobic molecules to demonstrate the potential of the nanogel to capture them from water. Hydrophobic molecules investigated in this study include carcinogenic aromatic hydrocarbon such as perylene, anthracene, phenanthrene, and 1-naphthyl amine. The hydrophilic molecules selected in our study include calcein (organic dye) and propranolol hydrochloride (pharmaceutical). Typically, concentration of the micropollutants present in drinking water is in the range of nanomolar to micromolar concentrations. Hence, we have artificially contaminated the water with different micropollutants with a final concentration of $100 \mathrm{nM}$. Final concentration of DNA nanoparticles used in our study was $500 \mathrm{nM}$. Typically, Y-DNA/Ad-8 nanoparticle in PBS buffer $(100 \mu \mathrm{L})$ containing $\mathrm{NaCl}(100 \mathrm{mM})$ was added into water containing micropollutant solution $(400 \mu \mathrm{L})$, shaken for $1 \mathrm{~min}$ and kept undisturbed for about $10 \mathrm{~min}$. In the cases of hydrophobic micropollutants, they were initially dissolved in acetone and diluted with water to $400 \mu \mathrm{L}$. Since the concentration of the micropollutants present in all these cases is $100 \mathrm{nM}$, we have used very sensitive fluorescence spectroscopy as the tool to follow the capture of micropollutants. This was studied by comparing florescence intensity changes of the micropollutants before and after DNA nanoparticle addition to their solution.

Initially, the biocompatibility of the nanogel was analyzed with two different cancer cell lines (HeLa and A549) by means of 3-(4,5-dimethylthiazol-2-yl)-2,5-diphenyltetrazolium
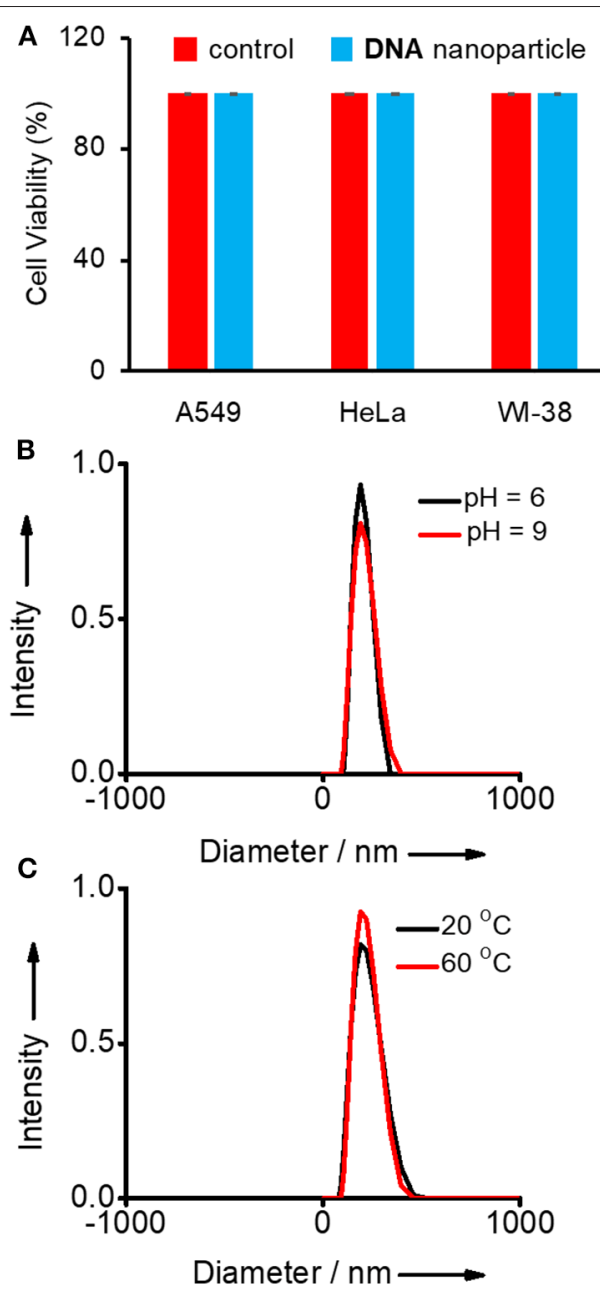

FIGURE 2 | (A) Comparison of viability of A549, HeLa (cancer cells), and WI-38 (normal cell) cell lines treated with Y-DNA/Ad-8 nanoparticles. Size distribution of nanoparticle obtained from the DLS analyses (B) at two different $\mathrm{pH}$ and (C) at two different temperatures. 
bromide (MTT) assay. The viability of untreated HeLa, A549, and WI-38 cells were taken as $100 \%$. In order to assess the biocompatibility of Y-DNA/Ad-8 nanoparticle, A549, HeLa (cancer cells), and WI-38 (normal cell) cells were incubated with Y-DNA/Ad-8 nanoparticles for $24 \mathrm{~h}$. The concentration of YDNA/Ad-8 nanoparticle used for MTT assay was $500 \mathrm{nM}$. As expected, MTT assay reveals cell viability above $95 \%$ for all cell lines demonstrating excellent biocompatibility of Y-DNA/Ad8 nanoparticles (Figure 2A). Furthermore, thermal and $\mathrm{pH}$ stabilities of the nanoparticles under different experimental conditions were studied by DLS analyses. DLS analyses of the nanoparticle at $\mathrm{pH} 6$ and 9 show no difference in the size distribution of the nanoparticle, which clearly show the pH stability of the nanoparticle (Figure 2B). Similarly, thermal stability of the nanoparticle was studied at 20 and $60^{\circ} \mathrm{C}$ and in this case also no noticeable change was observed for the size distribution of the nanoparticles (Figure 2C). These results reveal the thermal and pH stability of Y-DNA/Ad-8 nanoparticles.

After confirming the biocompatibility and stability of $\mathbf{Y}$ DNA/Ad-8 nanoparticles, we have carried out the micropollutant capture experiments with the nanoparticles. It is to be mentioned that the hydrophobic micropollutants selected in our study showed very poor solubility in water. Emission spectrum of perylene in water shows its characteristic emission with emission maximum centered at $440 \mathrm{~nm}\left(\lambda_{\text {exc }}=400 \mathrm{~nm}\right.$ ) (Figure 3A and Figure S2). Very interestingly, a significant enhancement in emission intensity ( 9 fold) was observed with the addition of Y-DNA/Ad-8 nanoparticles, which can be attributed to the capturing of feebly water-soluble perylene into the hydrophobic cavities of the nanoparticle. It is also to be noted that a redshift of $3 \mathrm{~nm}$ was observed for the emission peak at $440 \mathrm{~nm}$.
These results collectively suggest that perylene binds efficiently to the nucleobases through $\pi$-stacking interactions as reported in similar systems (Sezi and Wagenknecht, 2013; Gershberg et al., 2015). The red-shift in the emission peak suggest that the perylene reside in the hydrophobic environments after their capture from water. The possibility of non-covalent trapping of perylene in the hydrophobic pockets of the nanoparticle cannot be completely ruled out. From the fluorescence titration experiments we have calculated the capture efficiency of the nanoparticle as $500 \mathrm{nM}$ of Y-DNA/Ad-8 nanoparticle was able to capture $1 \mu \mathrm{M}$ of perylene. Anthracene was nearly insoluble in water as evident from its fluorescence spectrum $\left(\lambda_{\text {exc }}=400 \mathrm{~nm}\right)$ in water. However, efficient capturing of anthracene by the nanoparticles caused a dramatic increase in the fluorescence intensity (Figure 3B). In this case as well, $\pi$-stacking with the nucleobases and hydrophobic interactions are responsible for the capturing of anthracene by the DNA nanoparticles. It is also to be noted that the excimer emission with maximum centered at $410 \mathrm{~nm}$ dominates in the emission spectrum due to the aggregation of anthracene in the hydrophobic environment of the nanoparticle (Neelakandan and Ramaiah, 2008). Fluorescence spectrum of phenanthrene in water clearly reveals that it is nearly insoluble in water. However, a significant enhancement in emission intensity was observed with the addition of nanoparticle into the solution due to the efficient capture of phenanthrene by the nanoparticles (Figure 3C). It is also worth noting that phenanthrene shows mainly excimer-like emission centered at $408 \mathrm{~nm}\left(\lambda_{\text {exc }}=280 \mathrm{~nm}\right)$ after their capture (Haynes et al., 1990), which clearly suggest that phenanthrene exists as aggregated species in the nanogel assembly. This observation is in good agreement with other hydrophobic molecules. We have also
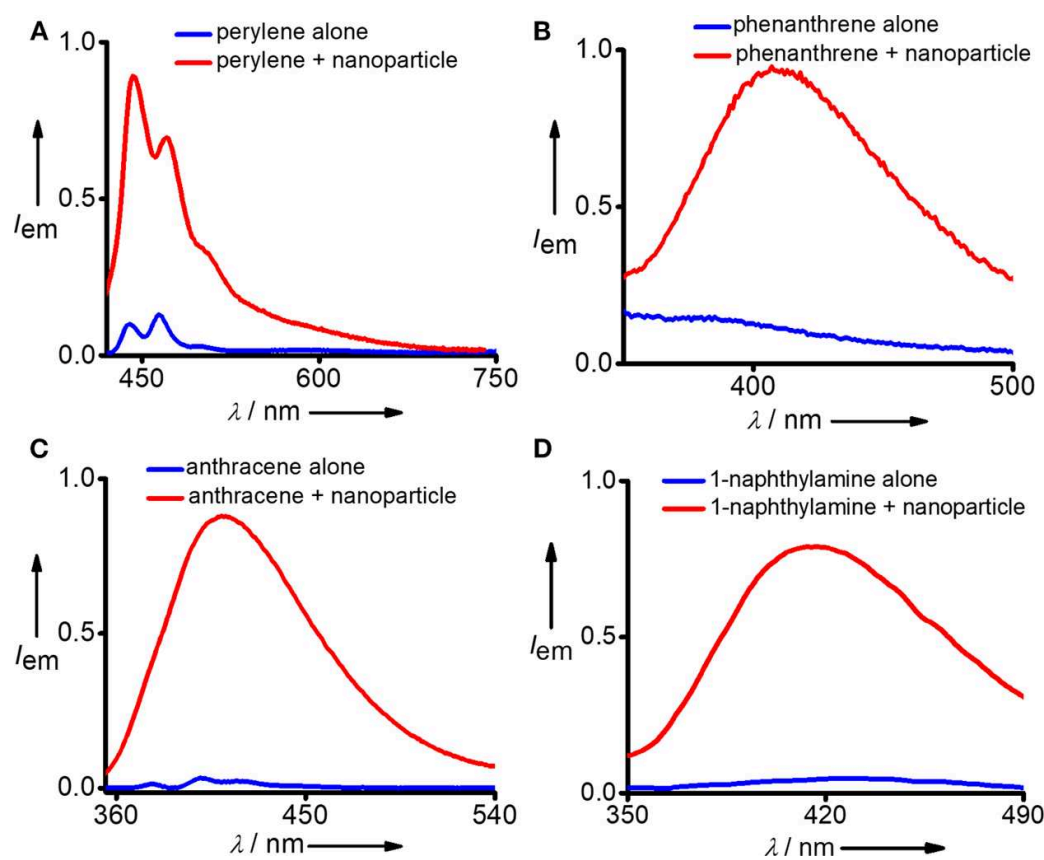

FIGURE 3 | Comparison of fluorescence spectra of (A) perylene, (B) phenanthrene, (C) anthracene, and (D) 1-naphthylamine before and after the addition of Y-DNA/Ad-8 nanoparticles. 

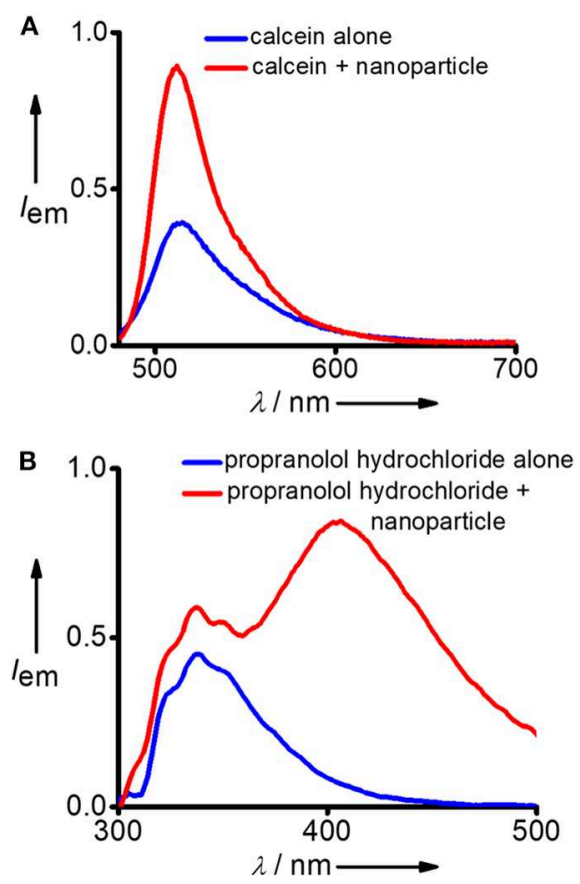

FIGURE 4 | Comparison of fluorescence spectra of (A) calcein and (B) propranolol hydrochloride before and after the addition of Y-DNA/Ad-8 nanoparticles.

demonstrated the capture of 1-naphthylamine (Figure 3D). A dramatic increase in fluorescence intensity was observed with the capture of poorly water soluble 1-naphthylamine by the nanoparticles. In this case as well, only excimer-like redshifted peak centered at $415 \mathrm{~nm}\left(\lambda_{\text {exc }}=270 \mathrm{~nm}\right)$ was observed due to the aggregation of 1-naphthylamine in Y-DNA/Ad-8 nanoparticle network.

After successful demonstration of the capture of hydrophobic micropollutants, we have extended our study toward the capture of hydrophilic micropollutants in water. We have taken calcein as a representative hydrophilic organic dye. Calcien is water soluble and it exhibits the characteristic emission spectrum with maximum centered at $512 \mathrm{~nm}\left(\lambda_{\text {exc }}=470 \mathrm{~nm}\right)$. Interestingly, an increase in emission intensity was observed after the incubation with DNA nanoparticles (Figure 4A). This observation suggests that though calcien is water soluble, it is weakly aggregated in water and upon binding with the Y-DNA/Ad-8 nanoparticle through non-covalent interactions dissociate the weakly assembled calcien aggregated species into the corresponding monomeric species, which resulted in an increase in emission intensity. Another hydrophilic molecule we have investigated in this study is propranolol hydrochloride, which is a pharmaceutical molecule. Propranolol hydrochloride is cationic molecule and is water soluble. This molecule shows its characteristic emission centered at $335 \mathrm{~nm}\left(\lambda_{\text {exc }}=\right.$ $270 \mathrm{~nm}$ ) in water (Figure 4B). Interestingly, in addition to the characteristic emission of propranolol hydrochloride at $335 \mathrm{~nm}$, a new red-shifted peak centered at $405 \mathrm{~nm}$ also emerges after its incubation with Y-DNA/Ad-8 nanoparticles. This suggest that positively charged propranolol hydrochloride efficiently binds to the negatively charged DNA backbone through electrostatic interactions with its hydrophobic naphthalene residue interact with the nucleobases through $\pi-\pi$ stacking interactions. The emergence of red-shifted excimer-like peak suggest that the molecule is getting aggregated inside the nanogel network after their capture by the Y-DNA/Ad-8 nanoparticles.

\section{CONCLUSIONS}

In summary, we have reported the synthesis of physically cross-linked DNA nanoparticles through multivalent hostguest interaction between $\beta$-CD functionalized branched DNA nanostructures as the host and a star-shaped adamantylterminated 8-arm poly(ethylene glycol) polymer as the guest. The most remarkable structural features of DNA nanoparticles include their excellent biocompatibility and the possibility of various non-covalent interactions with both hydrophobic and hydrophilic organic molecules. We have demonstrated the potential of DNA nanoparticles for the rapid and efficient capture of various micropollutants typically present in water including carcinogens (hydrophobic micropollutants), organic dyes (hydrophilic), and pharmaceutical molecules (hydrophilic). The capture of micropollutants by DNA nanoparticles was attributed to the various non-covalent interactions between DNA nanoparticles and the micropollutants. The excellent biocompatibility of the DNA nanoparticles and their potential as an efficient capture of both poorly water soluble hydrophobic micropollutants and highly water soluble hydrophilic micropollutants may motivate other researches to explore DNA-based nanomaterials as an adsorbent for the removal and purification of micropollutants from drinking water.

\section{DATA AVAILABILITY STATEMENT}

All datasets generated for this study are included in the article/Supplementary Material.

\section{AUTHOR CONTRIBUTIONS}

RV designed the project. SA, HT, DP, and $\mathrm{KH}$ performed all the experiments. RV and SA co-wrote the manuscript. All authors analyzed the data and commented on the manuscript.

\section{FUNDING}

Financial supports from DBT (BT/PR30172/NNT/28/1593/2018) and KSCSTE (KSYSA) are gratefully acknowledged.

\section{ACKNOWLEDGMENTS}

We thank UGC and CSIR for research fellowships.

\section{SUPPLEMENTARY MATERIAL}

The Supplementary Material for this article can be found online at: https://www.frontiersin.org/articles/10.3389/fchem. 2020.00002/full\#supplementary-material 


\section{REFERENCES}

Aldaye, F. A., Palmer, A. L., and Sleiman, H. F. (2008). Assembling materials with DNA as the guide. Science 321, 1795-1799. doi: 10.1126/science.1154533

Alsbaiee, A., Smith, B. J., Xiao, L., Ling, Y., Helbling, D. E., and Dichtel, W. R. (2016). Rapid removal of organic micropollutants from water by a porous $\beta$-cyclodextrin polymer. Nature 529, 190-194. doi: 10.1038/nature16185

Barnes, J. C., Jurícek, M., Strutt, N. L., Frasconi, M., Sampath, S., Giesener, M. A., et al. (2012). ExBox: a polycyclic aromatic hydrocarbon scavenger. J. Am. Chem. Soc. 135, 183-192. doi: 10.1021/ja307360n

Feldkamp, U., and Niemeyer, C. M. (2006). Rational design of DNA nanoarchitectures. Angew. Chem. Int. Ed. 45, 1856-1876. doi: 10.1002 /anie. 200502358

Gao, Y., Li, Y., Zhang, L., Huang, H., Hu, J., Shah, S. M., et al. (2012). Adsorption and removal of tetracycline antibiotics from aqueous solution by graphene oxide. J. Colloid Interface Sci. 368, 540-546. doi: 10.1016/j.jcis.2011.11.015

Gershberg, J., Stojkovic', M. R., Škugor, M., Tomic', S., Rehm, T. H., Rehm, S., et al. (2015). Sensing of double-stranded DNA/RNA secondary structures by water soluble homochiral perylene bisimide dyes. Chem. Eur. J. 21, 7886-7895. doi: 10.1002/chem.201500184

Gothelf, K. V., and LaBean, T. H. (2005). DNA-programmed assembly of nanostructures. Org. Biomol. Chem. 3, 4023-4037. doi: 10.1039/b510551j

Hannah, K. C., and Armitage, B. A. (2004). DNA-Templated assembly of helical cyanine dye aggregates: a supramolecular chain polymerization. Acc. Chem. Res. 37, 845-853. doi: 10.1021/ar030257c

Haynes, D. R., Helwig, K. R., Tro, N. J., and George, S. M. (1990). Fluorescence quenching of the phenanthrene excimer on AI20 3(0001): coverage and distance dependence. J. Chem. Phys. 93, 2836-2847. doi: 10.1063/1.458869

Jiang, Q., Song, C., Nangreave, J., Liu, X., Lin, L., Qiu, D., et al. (2012). DNA Origami as a carrier for circumvention of drug resistance. J. Am. Chem. Soc. 134, 13396-13403. doi: 10.1021/ja304263n

Jones, M. R., Seeman, N. C., and Mirkin, C. A. (2015). Nanomaterials. Programmable materials and the nature of the DNA bond. Science 347, 1260901-1260911. doi: 10.1126/science.1260901

Kuo, C. Y. (2009). Comparison with as-grown and microwave modified carbon nanotubes to removal aqueous bisphenol A. Desalination 249, 976-982. doi: 10.1016/j.desal.2009.06.058

Mishra, A., Korlepara, D. B., Kumar, M., Jain, A., Jonnalagadda, N., Bejagam, K., et al. (2018). Biomimetic temporal self-assembly via fueldriven controlled supramolecular polymerization. Nat Commun. 9:1295. doi: 10.1038/s41467-018-03542-z

Modi, S., Nizak, C., Surana, S., Halder, S., and Krishnan, Y. (2013). Two DNA nanomachines map $\mathrm{pH}$ changes along intersecting endocytic pathways inside the same cell. Nat. Nanotechnol. 8, 459-467. doi: 10.1038/nnano.2013.92

Neelakandan, P. P., and Ramaiah, D. (2008). DNA-Assisted long-lived excimer formation in a cyclophane. Angew. Chem. Int. Ed. 47, 8407-8411. doi: 10.1002/anie.200803162

Órfão, J. J. M., Silva, A. I. M., Pereira, J. C. V., Barata, S. A., Fonseca, I. M., Faria, P. C. C., et al. (2006). Adsorption of a reactive dye on chemically modified activated carbons-influence of pH. J. Colloid Interf. Sci. 296, 480-489. doi: 10.1016/j.jcis.2005.09.063

Pinheiro, A. V., Han, D., Shih, W. M., and Yan, H. (2011). Challenges and opportunities for structural DNA nanotechnology. Nat. Nanotechnol. 6, 763-772. doi: 10.1038/nnano.2011.187

Rest, C., Mayoral, M. J., Fucke, K., Schellheimer, J., Stepanenko, V., and Fernandez, G. (2014). Self-assembly and (Hydro)gelation triggered by cooperative $\pi-\pi$ and Unconventional C-H . X X hydrogen bonding interactions. Angew. Chem. Int. Ed. 53, 700-705. doi: 10.1002/anie.201307806
Schwarzenbach, R. P., Escher, B. I., Fenner, K., Hofstetter, T. B., Johnson, C. A., Gunten von, U., et al. (2006). The challenge of micropollutants in aquatic systems. Science 313, 1072-1077. doi: 10.1126/science.11 27291

Seeman, N. C. (1982). Nucleic acid junctions and lattices J. Theor. Biol. 99, 237-247. doi: 10.1016/0022-5193(82)90002-9

Seeman, N. C. (2003). DNA in a material world. Nature 421, 427-431. doi: $10.1038 /$ nature 01406

Seeman, N. C. (2010). Nanomaterials based on DNA. Annu. Rev. Biochem. 79, 65-87. doi: 10.1146/annurev-biochem-060308-102244

Sezi, S., and Wagenknecht,. H.-A. (2013). DNA-templated formation of fluorescent self-assembly of ethynyl pyrenes. Chem. Commun. 49, 9257-9259. doi: $10.1039 / \mathrm{c} 3 \mathrm{cc} 44733 \mathrm{~b}$

Song, C., Wang, Z.-G., and Ding, B. (2013). Smart nanomachines based on DNA self-assembly. Small 9, 2382-2392. doi: 10.1002/smll.201300824

Taniguchi, Y., Takishita, T., Kawai, T., and Nakashima, T. (2016). End-to-end self-assembly of semiconductor nanorods in water by using an amphiphilic surface design. Angew. Chem. Int. Ed. 55, 2083-2086. doi: 10.1002/anie.2015 09833

Thelu, H. V. P., Albert, S. K., Golla, M., Krishnan, N., Ram, D., Srinivasula, S. M., et al. (2018). Size controllable DNA nanogels from the self-assembly of DNA nanostructures through multivalent host-guest interactions. Nanoscale 10, 222-230. doi: 10.1039/C7NR06985E

Tørring, T., Voigt, N. V., Nangreave, J., Yan, H., and Gothelf, K. V. (2011). DNA origami: a quantum leap for self-assembly of complex structures. Chem. Soc. Rev. 40, 5636-5646. doi: 10.1039/c1cs15057j

Um, S. H., Lee, J. B., Park, N., Kwon, S. Y., Umbach, C. C., and Luo, D. (2006). Enzyme-catalysed assembly of DNA hydrogel. Nat. Mater. 5, 797-801. doi: $10.1038 /$ nmat 1741

Walsh, A. S., Yin, H., Erben, C. M., Wood, M. J. A., and Turberfield, A. J. (2011). DNA cage delivery to mammalian cells. ACS Nano 5, 5427-5432. doi: 10.1021/nn2005574

Wang, W., Xu, Z., Zhang, X., Wimmer, A., Shi, E., Qin, Y., et al. (2018). Rapid and efficient removal of organic micropollutants from environmental water using a magnetic nanoparticles-attached fluorographenebased sorbent. Chem. Eng. J. 343, 61-68. doi: 10.1016/j.cej.2018. 02.101

Xu, J., Wang, L., and Zhu, Y. (2012). Decontamination of Bisphenol A from aqueous solution by graphene adsorption. Langmuir 28, 8418-8425. doi: 10.1021/la301476p

Yu, S., Hu, J., Pan, X., Yao, P., and Jiang, M. (2006). Stable and pH-sensitive nanogels prepared by self-assembly of chitosan and ovalbumin. Langmuir 22, 2754-2759. doi: 10.1021/la053158b

Zhou, X., Pathak, P., and Jayawickramarajah, J. (2018). Design, synthesis, and applications of DNA-macrocyclic host conjugates. Chem. Commun. 54, 11668-11680. doi: 10.1039/C8CC06716C

Conflict of Interest: The authors declare that the research was conducted in the absence of any commercial or financial relationships that could be construed as a potential conflict of interest.

Copyright $\odot 2020$ Atchimnaidu, Thelu, Perumal, Harikrishnan and Varghese. This is an open-access article distributed under the terms of the Creative Commons Attribution License (CC BY). The use, distribution or reproduction in other forums is permitted, provided the original author(s) and the copyright owner(s) are credited and that the original publication in this journal is cited, in accordance with accepted academic practice. No use, distribution or reproduction is permitted which does not comply with these terms. 